\title{
Article
}

\section{A Dynamic Knowledge Management Framework for the High Value Manufacturing Industry}

Piorkowski, Barry Andrew, Gao, James Xiaoyu, Evans, Richard David and Martin, Nick

Available at http://clok.uclan.ac.uk/5720/

Piorkowski, Barry Andrew, Gao, James Xiaoyu, Evans, Richard David and Martin, Nick (2013) A Dynamic Knowledge Management Framework for the High Value Manufacturing Industry. International Journal of Production Research, 51 (7). pp. 2176-2185. ISSN 0020-7543

It is advisable to refer to the publisher's version if you intend to cite from the work. http://dx.doi.org/10.1080/00207543.2012.709650

For more information about UCLan's research in this area go to http://www.uclan.ac.uk/researchgroups/ and search for < name of research Group>.

For information about Research generally at UCLan please go to http://www.uclan.ac.uk/research/

All outputs in CLoK are protected by Intellectual Property Rights law, including Copyright law. Copyright, IPR and Moral Rights for the works on this site are retained by the individual authors and/or other copyright owners. Terms and conditions for use of this material are defined in the policies page.

\section{CLoK}

Central Lancashire online Knowledge www.clok.uclan.ac.uk

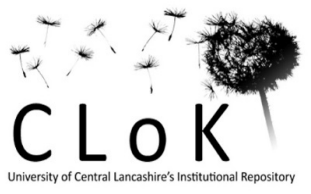




\section{A Dynamic Knowledge Management Framework for the High Value Manufacturing Industry}

Barry Andrew Piorkowski ${ }^{1}$, Richard David Evans ${ }^{2}$, Nick Martin $^{3}$ and James Xiaoyu $\mathrm{Gao}^{2 *}$

${ }^{1}$ Computer and Technology Building, University of Central Lancashire, Preston, PR1 2HE. UK

${ }^{2}$ Centre for Innovative Product Development, School of Engineering, University of Greenwich, Chatham Maritime, Kent, ME4 4TB, UK. Email: j.gao@gre.ac.uk

${ }^{3}$ BAE Systems Electronic Systems, Airport Works, Rochester, Kent, ME1 2XX, UK 
A Dynamic Knowledge Management Framework for the High Value Manufacturing Industry

Dynamic Knowledge Management (KM) is a combination of cultural and technological factors, including the cultural factors of people and their motivations, technological factors of content and infrastructure and, where these both come together, interface factors. In this paper a Dynamic KM framework is described in the context of employees being motivated to create profit for their company through product development in high value manufacturing. It is reported how the framework was discussed during a meeting of the collaborating company's (BAE Systems) project stakeholders. Participants agreed the framework would have most benefit at the start of the product lifecycle before key decisions were made. The framework has been designed to support organisational learning and to reward employees that improve the position of the company in the market place.

Keywords: knowledge; profit; product; lifecycle

\section{Introduction}

In the age before scribes, the printing press and computers, learning was shared through verbal communication based on the storyteller's interpretation of past events. When the story is passed on through word of mouth it can evolve and be slightly different each time told. Technological advancement has meant that events can now be captured in a wide variety of media formats that form a body of knowledge which shapes future civilised progression. There is a plethora of Knowledge Management (KM) technologies and approaches available. They range from those which are orientated more toward people and those which are orientated more towards systems (Gunasekaran and Ngai, 2007, Barnett et al., 2010). A summary of some of the strengths, weaknesses, opportunities and threats of some of the more widespread tools in industry is presented in Table 1. 
Aspiring to manage knowledge effectively seems logical and good business sense. Despite this, real evidence to prove the efficacy of $\mathrm{KM}$ is scarce in the literature. An anecdotal figure of $20 \%$ has been suggested as an improvement in sales or a reduction in overheads when implementing KM (Milton, 2007). The actual tangible numbers of financial benefits of quality, lean and statistical approaches in manufacturing for continuously improving processes, narrowing defect metrics and reducing costs are also difficult to find in peer reviewed publications. Big names in industry such as General Electric (Henderson and Evans, 2000), Motorola (Kumar and Gupta, 1993) and Toyota (Spear and Bowen, 1999) have indicated that business success is due to the application of a continuous improvement ethos. However, it remains difficult to pin-point cause and effect within the complex nature of global economies. 
Table 1. Knowledge Management Tools (Author's Own Creation).

Increasing System Orientation

- $\quad$ Structured Query Language (SQL), Systems

Application Products (SAP)

Oracle

Enterprise Resource Planning (ERP).

Interoperability of systems with web tools plus Semantic Web

3.0 or International standards which may include:-

- $\quad$ eXtensible Mark-up Language (XML)

Resource Description Framework (RDF)

Web Ontology Language (OWL)

- Automated Results when linked to a Search Engine for Data Mining / Statistical Analysis

Automated transactions when programmed according to Business Rules.

- Expensive due to the time needed to design, build and

Errors in Data Entry errors and coding Bugs can crash the system and loss of trust

Specific training may need to be given

- $\quad$ Speed up end-to-end process tim

- Save money by reducing labour costs.

亏ิ̀े

- $\quad$ Rejected system by users

Obsolescence

Costs greater than benefit

Dependency.

\section{Documentation Documentation} Computer tools for formal electronic or printed communication

calculations which may include files such as.-

- $\quad$ Adobe Acrobat Printed Document Format (PDF)

Computer Aided Design (CAD)

Microsoft Word docs

Microsoft PowerPoint presentation

Microsoft Excel spread sheet

Modelling Diagrams
System Diagrams (UML, SysML)

Widespread acceptance

Easy to use, print, edit and distribute

Linked to a Search Engine can be found easily if they

Linked to a Search Engine can be found easily if they
have a standardised naming convention, assigned metadata or folder structure.

- Slow approval for publication

Difficult to find documents if no standardised naming

convention, assigned meta-data or folder structure

Duplication can lead to confusion and loss of trust.

Out-of-date documents can lead to confusion and loss of trust.

- Poorly written documents can lead to confusion and loss of trust.

- Formalisation of concepts in print to be used as reference material.
Online Communities Open-Source projects and organic informal user generated Web 2.0 content and communication delivered through:Groupware and Social Media which may include:-

- Blogs

- Online Forums, Discussion Board

- WiKi's

These are made possible using web tools such as:-

- Hypertext Transfer Protocol (HTTP)

- $\quad$ Hypertext Preprocessor (PHP) language

Transmission Control Protocol/Internet Protoco

- HyperText Markup Language (HTML)

- Adobe Flash.

Rapid generation and distribution of collaborative content Organic production directly by user community so that Organic production directly by user community so that
most relevant and up to date issues of the community are maintained

- Rich in text and keywords for optimised Search Engine results.

- Inaccuracies if un-moderated

Security issues if un-moderated

Irrelevant comments may lead to loss of trust

Offensive comments may lead to loss of trust

Duplication can lead to confusion and loss of trus

- Poorly written content can lead to confusion and loss of trust.

- Professional networks built with connectivity of people at Professional

various times.

Widens participation at different times and locations.

- Security leak

- IP leaks.
Meetin include. Types of meeting can include:-

- Mentoring and Tutorials

- Job Shadowin

- Interview

- Focus-Groups, Committees, Forums and Working

Groups, Think Tanks

- $\quad$ Reviews

Meetings can either in the same geographical location and also facilitated through Video / Tele Conferencing applications such

- Cisco TelePresence

Microsoft LiveMeeting
Cisco WebEx.

Instant response and answers to questions from participants

- Instant update on status of progress reports

Instant collaboration on options for organic decision making.

- $\quad$ Loss of memory

Restricted involvement and contributions to those in attendance

- Travel costs expensive

Network bandwidth costs expensive.

Professional networks built and maintaine

Quick turnaroun

\section{- Single points of failure}

- Recurring issues

Conflicting personalities and agendas 


\section{Knowledge Management Styles}

Choi and Lee (2003) defined different KM styles for grouping purposes in their empirical investigation. The four different styles they chose are 'System-orientated', 'People-orientated', 'Dynamic' and 'Passive'. The 'Passive' style of KM is where the organisation has not formally implemented any type of KM. The 'System-orientated' style of KM relies on a structured database or information system. The 'Peopleorientated' approach is where the organisation promotes a culture of communication where people get together to discuss learning before, during and after events. The 'Dynamic' KM style, first theorised by Nonaka (1994) as dynamic spiral of knowledge creation depending on the direction of flow of information between people (informal/tacit) and multimedia (formal/explicit) is more costly to implement than the other styles. The researchers did, however, find that Dynamic KM yields the highest company performance over other KM style groups (Choi and Lee, 2003). The Dynamic KM style overcomes the drawbacks of using the informal 'People-orientated' or the formal 'System-orientated' style alone since it is a combination of technological and cultural factors.

Although it is known that the Dynamic KM style can return the greatest yield for a company in Korea, a Dynamic KM framework for product development in high value manufacturing or method of implementation has not been evaluated. This would be an important contribution to the literature since the retrospective analysis of performance based on survey respondents' perception of past events is very different to the live capture of real events during the product development journey. Since product development is about producing something that can be sold, KM should, therefore, be closely linked to performance so that people can profit from the value of knowledge. 
There is a gap in the literature for a dynamic KM framework that, when implemented, could aid the development of personal and product knowledge. This paper aims to provide a conceptual framework for dynamic $\mathrm{KM}$ and discusses the wider issues associated with managing knowledge and performance in high value manufacturing industry.

\section{Methodology}

Research can be described as providing evidence of systematic investigation and learning that can solve a problem or answer a question that is unknown. This study endeavoured to balance the both Naturalistic and Constructivist methodologies by approaching the research holistically mixing both qualitative and quantitative methods where appropriate. This included an extensive period of ethnographic pilot work which was undertaken in order to learn the specific terminology and begin to understand the cultural nuances of BAE Systems. A deep exploration of the physical and electronic landscape of the company was performed. Informal discussions, telephone conversations and electronic communication with the populous aided the investigator to navigate to challenging areas where change may improve the future life and effectiveness of the people within the organisation.

A dynamic knowledge management framework was systematically developed following a series of cooperative meetings with BAE Systems project stakeholders. A prototype meeting capture and indexing tool was used to video, record and publish on the company intranet the discussion linked to both personal and product development. 


\section{Tiers of the Proposed Dynamic KM Framework}

Technological factors of KM have be presented in a tiered architecture (Chua, 2004), which has been expanded by the authors of this paper to include cultural tiers of people and motivation. This section discusses the previous work in the literature for each of those tiers.

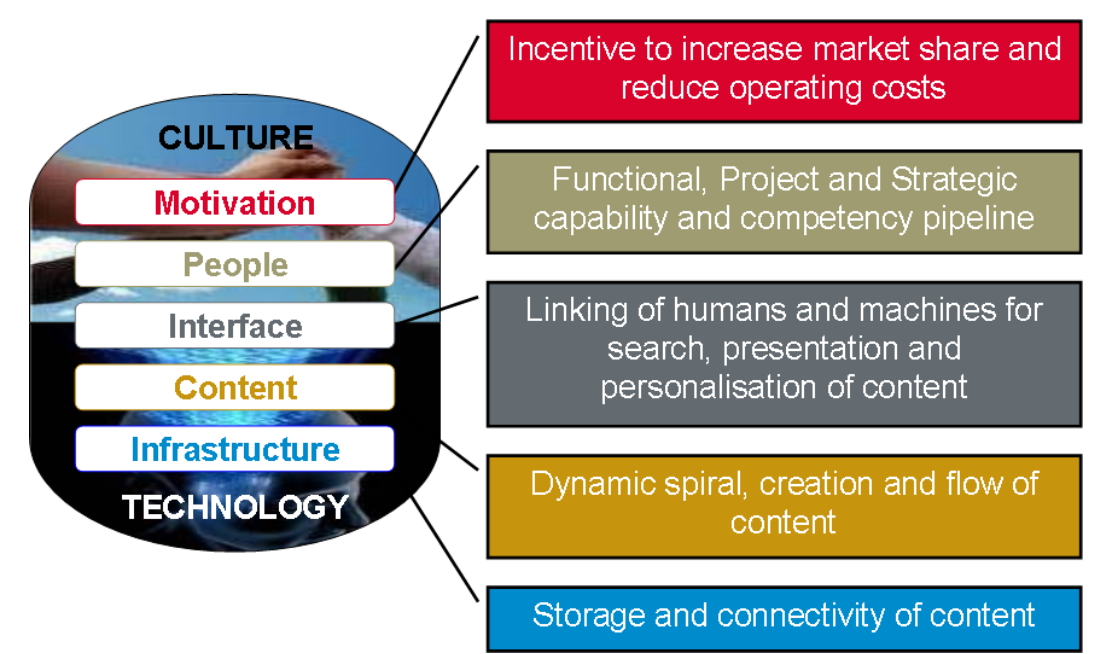

Figure 1. Tiers of Dynamic KM (Authors Own Creation).

The technological levels are infrastructure, content and interface services. The interface level is where technology meets the two cultural aspects of Dynamic KM (Figure 1). The people (individuals, teams and organisational structure), how they work together and their motivations are all cultural factors of KM.

\section{Motivation}

Historically, organisations have attempted to motivate people to behave in a certain way around the world. This concept of controlling people has transcended religious, business and academic societies alike. Controlling or managing people gets harder as the group gets larger where it becomes more difficult to maintain trusted relationships (Serenko et al., 2007). It is still possible to control large populations and in a capitalist society this is 
generally linked in some way to currencies of value like money and resources. There can be other, non-monetary ways of providing an incentive for people. Mental states can change with the application or withdrawal of an incentive and each person is unique. Research by questionnaire has identified individual psychological determinants of attempting knowledge transfer. These are the perceived judgment in breadth, selfefficacy performance (confidence), openness in personality and perceived support from others (Cabrera et al., 2006). In an earlier study, perceived greater organisational reward is a motive for employees to contribute outside their work unit. Personal gain in upward mobility within the organisation motivates employees to search for answers outside their work unit (Burgess, 2005).

Motivation in the Dynamic KM framework is the incentive for people within the organisation to increase market share and reduce operating costs. Motivated people increasing shareholder value are more likely to secure their own and colleagues future employment. The organisational performance and the success of Dynamic KM are dependent on the people and their motivations.

\section{People}

Leadership at the top of an organisation would like to believe that they have motivated people to perform according to a policy of set principles through an appraisal or Performance Development Review (PDR) process. This is not always the case in complex industries and it is the unpredictability of human behaviour that drives error, change and learning. Individuals are unique with their own story and life journey history which means that each person therefore can categorise and value the same event in a different way to provide conflicting information biased according to personal interest or gain (Parasuraman and Wickens, 2008, Snowden and Boone, 2007). Likewise, the same 
person may interpret the same event differently depending on how they feel relative to their location and their function in time and space. The differences within people and between people mean that the resultant performance of people to achieve desired outcomes is also variable. People have physiological and biomechanical limits with psychological and sociological boundaries that constrain performance. Learning styles, cognitive styles, thinking styles, decision making styles and personality types are closely related (Berings et al., 2005). When people learn they can expand their capabilities and improve their competency level of performing a capability. Listening to feedback and being open to change, therefore, enables learning from past experiences. If a mistake is not acknowledged with an open mindset then there is likelihood that the same error will be reproduced. However, past results do not always indicate future performance which is why there is always an element of risk to consider in decision making. Specific capabilities for an engineering organisation have been published. These were functional, project and strategic capabilities (Bredin, 2008, Bredin, 2010). Bredin generalised these capabilities from a whole organisational standpoint. It is thought by the authors of this paper that the concept can also be applied to individual employees. Self-management should be encouraged because it is individual employees who must take ownership of their own personal performance and understand the part they play in achieving organisational results. Functional capabilities that people may possess in product development are skills in changing and producing items for sale. Project capabilities can be how a person progresses a project through the PLM process. These may include communication, planning and general management skills. Strategic capabilities are how a person may visualise future market trends and needs so that the organisation is ready and can respond to demand. Functional, project and strategic capability all influence people capability (Bredin, 2008). The competency level of these 
capabilities is difficult to quantify and no attempt was published by the originating investigator in doing this when comparing two organisations. Instead, the researcher wanted to try and create a more elaborate understanding of effort (Bredin, 2010). Following on from that work, the authors of this paper suggest that perhaps the competency level of employees could be measured through success rates. For example, an employee involved with systems could be measured by how they have improved process times without compromising quality or cost. An employee involved with manufacturing could be measured by how they have reduced the cost per unit produced without compromising quality or time. Employees involved with projects could have their competency based on team churn rates, project delivery times, budget overspend and customer feedback. Employees involved with strategy could be measured on the profit margin and market dominance.

People are the most important part of Dynamic KM. Without people and their experiences there is no knowledge, only data and information. It is people, not machines, that are needed to investigate and make sense of complex situations.

\section{Interface}

When more than one person is involved in learning they become a team. These teams can be a formal reporting structure or shared understanding may become apparent though network analysis (Louadi, 2008, Carley et al., 2007). It is important to note, that due to the dynamic nature of human-to-human and human-to-machine relationships, people may change their behaviour and preferences depending on how they are feeling at that moment in time, function or location. Accordingly, caution is advised when considering deep detailed analysis of a network that includes people. People in teams perform best when they are well connected, working in harmony towards a common 
goal (Salas et al., 2008) with a shared understanding (Hertzum, 2008). Common expectations about team processes, results and roles in achieving the team's objective can be described as a shared mental model. However, agreeableness is not always conducive to progress and conflict forces people to challenge conventional thought. This is a common dilemma in Concurrent Engineering to both secure sales and make a profit on those sales. Conflict can occur between people during decision making where it is necessary to align unique customer needs with known standards (or vice versa). To survive in highly competitive, safety-critical markets such as aerospace there must be sufficient boundaries to meet quality commitments yet enough flexibility to allow for innovation. Finding the right balance to design for $\mathrm{x}(\mathrm{DFx})$ where $\mathrm{x}$ can be for manufacture, cost, assembly or test and considering 'trade-off's' is challenging. DFx requires many skills from team members during the PLM process who are also supported by team meetings, information communication technology systems and management charts to connect people and ideas together (Barczak et al., 2009, Pons, 2008, Kuo et al., 2001).

In meetings where people trust each other, truthful discussions can take place. The dialogue may include stories of past experiences with the presentation of ideas whereby group attendees predict the outcome of different options, then plan and decide on what action should be taken. The action taken will change either the operating environment to suit the behaviour, change the behaviour to suit the operating environment or a combination of both. Within the context of a product development business, changes usually are usually driven by the need to ethically reduce operating costs or increase market share so that there is a greater volume of products sold which are more profitable. The outcome of said actions does not always have the desired effect. This means that progression is a learning process, which requires time and effort. 
Further meetings follow up the action items from past meeting or there are sometimes even meetings to discuss how to approach a future meeting and so on. Meetings, therefore, offer an opportunity to identify who within an organisation uses knowledge to shape the successful development of a product. Meetings can take place spontaneously or they can be formal. The attendees can all attend a conventional co-located face-toface meeting or, with the aid of technology, asynchronous meeting content can grow organically.

Collaborative computing technology, often termed "groupware" is a variety of tools and technologies to facilitate communication and collaboration through virtual meetings in cyberspace (Attaran, 2007). These tools can be used both to virtually connect people together in different locations and as a capture technology for audit tracking and knowledge mapping purposes (Okada et al., 2008). Social network profiles, forums, blogs, Wiki's and video posts and other forms of user-driven web content have been popular ways of connecting people and ideas together without having to meet in person as often (Yao et al., 2008). Time and effort has created a world which would not have been possible without the collective endeavour of people being stored in machine code and continuously improved over countless lifetimes.

The interface level of Dynamic KM is how the people and the machines interact with each other to generate shareholder value. The role of a human or a machine can be interchanged for searching and presenting data and information. Humans are more suited to handling exceptions to rules and reasoning to create personalised knowledge; machines are more suited to data and information processing. 


\section{Content}

Content is a general term for a collection of documents, files, data, information etc. It can take a lot of time and effort to collect, publish and renew content. If employees do not use or trust the content held in the infrastructure, then the time and effort (with significant costs associated) taken to collect is wasted (Renzl, 2008). Also, if employees do try and access some content but cannot find what they are looking for, they will get frustrated. This occurrence happens less often due to improving the way users can interact with the content and also the user community. Web 2.0 refers to the second generation of web design that allows users to easily create, share, tag and connect content. Following on from this, there is a new generation of Wiki tools that supports the integration of Web 2.0 and Semantic Web 3.0 approaches (Noy et al., 2008). Semantic Web consists of machine readable content defined and encoded in a way that it can be used by machines not just for display purposes, but for automation and interoperability of content across various applications (Jin et al., 2008). The development of the Semantic Web depends on a shared understanding with structured mark-up languages using formally defined ontology encoding (Dadzie et al., 2009, Benn et al., 2008, Chen et al., 2008). This means that for the Semantic Web to work, online content needs to be codified with meta-tags such as keywords for search-optimised discovery and presentation. Alternatively, it is also possible to allow users to choose their own personalised tags after the content has been uploaded (Wang et al., 2010).

Content in Dynamic KM is the physical document library tagged with meta-data and also the web based online content so users are able to read, watch or listen. Consideration needs to be taken here for supported file extension types. 


\section{Infrastructure}

Infrastructure consists of the equipment, systems, software and services used across an organisation. Cybercrime is now one of the greatest threats to an organisation's infrastructure. A cyber-attack could be designed to disrupt business as usual processes or to have access to the content held within the infrastructure. Organisations can implement a number of security measures to reduce the risk of a breach. These include secured buildings, networks with firewalls, encryption keys and passwords. The downside to the increased infrastructure security is that it can be challenging and expensive opening up and giving access to content for selected collaborators or home workers. Another significant cost is storage. Some documents can be routinely weeded for deletion, but others need to be retained as a legal requirement because they are classified as a record.

The infrastructure level in Dynamic KM is the storage and connectivity of content with document archival, retention and retrieval systems with security access control.

Dynamic KM needs motivated people communicating with each other at meetings and using machines in an effort to create, update and share documents and other content within the organisational infrastructure in an effort to learn how to deliver greater value to the customer.

\section{The Dynamic KM Framework for High Value Manufacturing Industry}

The literature review detailed in the previous section aided the research team to define the proposed framework within the context of the high value manufacturing industry (Figure 2). In this case, developing the Dynamic KM concept into a feasible framework for high value manufacturing industry was achieved by making two assumptions, (1) 
that company employees are motivated to continuously improve their own skills required to meet business objectives rewarded through the Performance Development Review (PDR) process; and (2) employees are motivated to continuously improve the profitability of company products developed through the Product Lifecycle Management (PLM) process. These two processes are already mature in the high value manufacturing industry. The PDR appraisal is a common way to audit employee competence and is generally an indicator for remuneration packages. The PDR ensures that employees are paid accordingly for meeting business objectives. The collected data can also be used to identify organisational continuous improvement opportunities, such as where to fill knowledge gaps and mitigate risk in single points of failure. Capability and competence profiles linked to a search engine are useful when wanting to direct questions that require expert opinions. Those experts may also be asked to attend PLM phase review meetings and system integration events during product development. The outcome of the actions after what was decided in those meetings is an indicator of the level of expertise of those people involved.

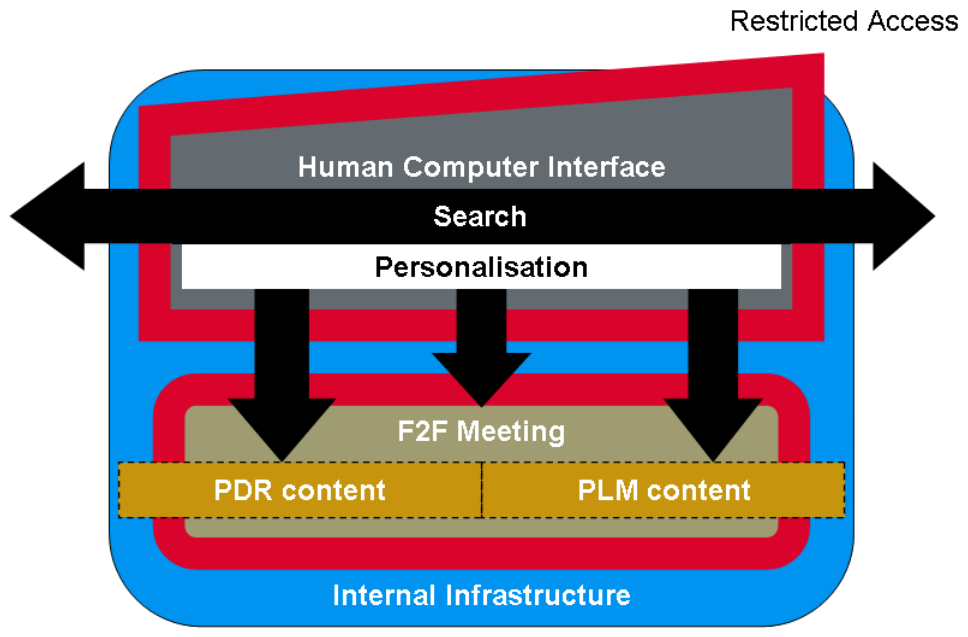

Figure 2. Dynamic KM Framework (Author's Own Creation).

The Dynamic KM framework includes restricted access to the internal infrastructure. The infrastructure allows the storage and connectivity of content which 
pertains to the company's people, products and processes. The proposed Dynamic KM Framework has two main interfaces. One is the human computer interface (HCI) to search both the internal (intranet, databases, enterprise software) and external infrastructure (internet). This interface also provides access control and personalised presentation of content depending on the end-users' viewing rights. The second interface is the human to human interface between people at face-to-face (F2F) meetings. The references to knowledge in conversations that take place at F2F meetings could be considered to be the most important to the current issues that are of value to a business. This is because the key people within an organisation are required to attend PLM review meetings to improve the sale and delivery of products. This means that the knowledge that they hold is vital to the success of the business. Both of the F2F and the HCI interfaces rely on a common understanding for smooth communication. It is important however, not to ignore conflict as this can lead to innovation. The framework depends on motivated people to actively seek, share and learn (Figure 2). This is signified with the colour red in the diagram. People and motivation are the cultural factors of the framework.

A prototype tool face-to-face $(\mathrm{F} 2 \mathrm{~F})$ meeting capture and indexing service was developed to enhance the framework (Piorkowski et al., 2011b, Piorkowski et al., 2011a). The prototype has utilised popular video conferencing, web production and groupware technology components and techniques. 


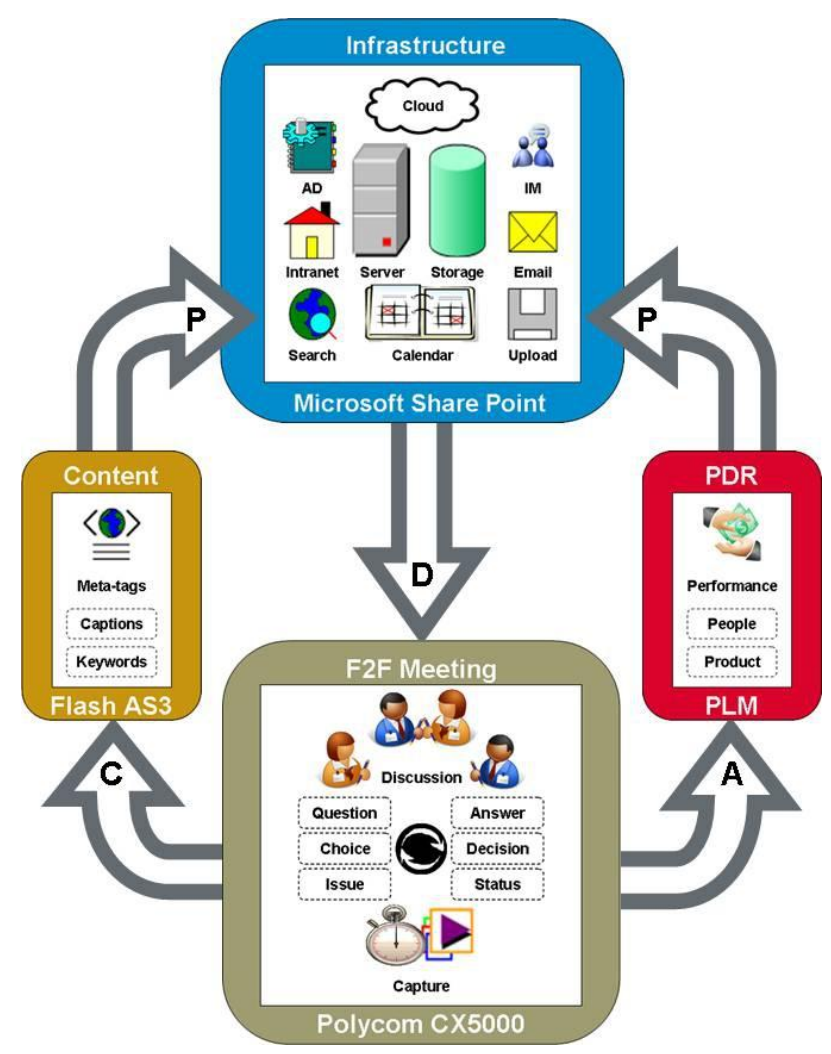

Figure 0.1 Prototype F2F Meeting Capture and Indexing Tool (Piorkowski et al., 2011b)

The prototype had been made to be interoperable with the Plan-Do-Check-Act (PCDA) continuous improvement cycle. This means that F2F meeting content is video captured. This may involve communication of what has been done during product development. Questions are answered and decisions made from options of choice and the status of issues discussed. This meeting content, through using the prototype service, can then be checked with others since it is made searchable with keyword and caption meta-tags in the organisational infrastructure. In this case, the infrastructure is provided by Microsoft ${ }^{\circledR}$ SharePoint (Microsoft Corporation, Reading UK). The Performance Development Review process for personal learning objectives and the Product Lifecycle Management process or business objectives should also provide a reflective feedback loop to learn after action for future planning. 
If people do not participate by accessing the interface services or are not motivated to learn and improve product profitability, then the framework and associated prototype is rendered useless. This is why Dynamic KM must be embedded as part of the PDR and PLM processes. People can then be rewarded for attempting to re-use knowledge for saving time and costs; creating new knowledge by problem solving and attempting to transfer knowledge to another person or product. How much they are rewarded can be derived from the financial value of that knowledge which can be calculated based on profitability metrics. A suggested breakdown of profitability factors in a high value manufacturing organisation as discovered by Piorkowski et al (2011a) is graphically depicted below (Figure 3).

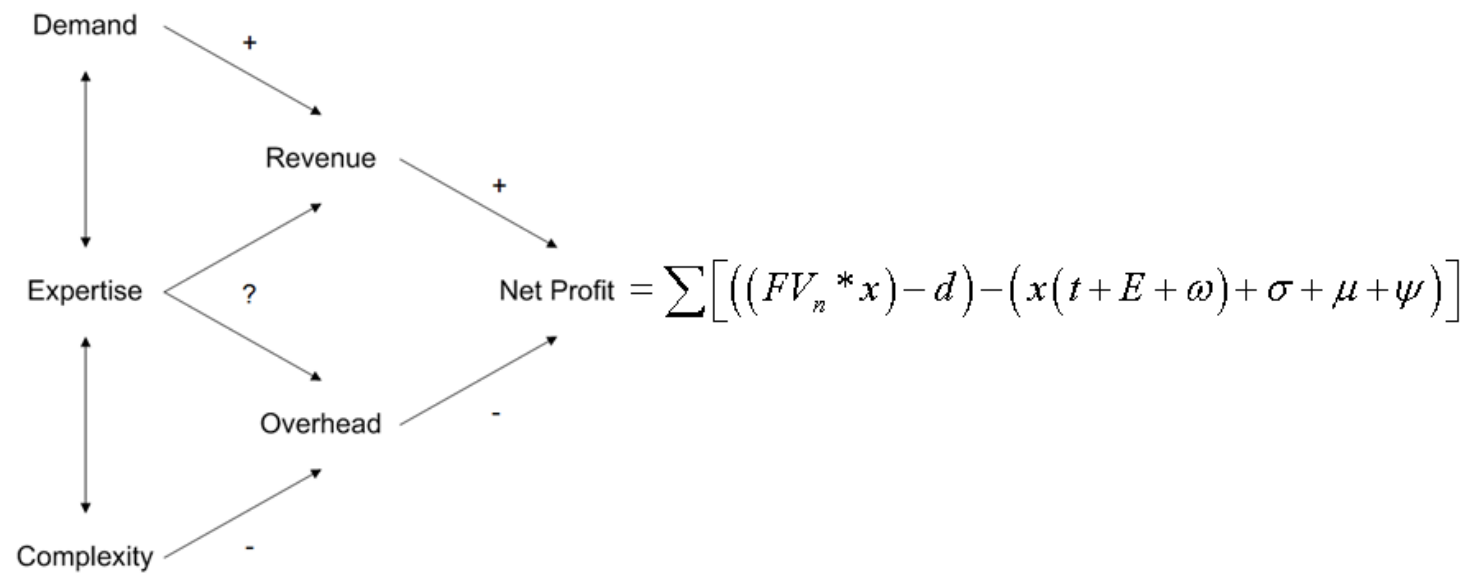

Figure 3. Factors Effecting Profit in an Organisation (Piorkowski et al., 2011a).

with

$$
F V_{n}=P V(1+r)^{n}
$$

$F V=$ Future Value after $\mathrm{n}$ periods $(\mathrm{GBP}) ; P V=$ Present Value $(\mathrm{GBP})$;

and

$r=$ Periodic rate of return; $n=$ Number of compounding periods; $x=$ Volume of sales (units); $d$ $=$ Returns costs $(\mathrm{GBP}) ; t=$ Labour costs $(\mathrm{GBP}) ; E=$ Materials costs $(\mathrm{GBP}) ; \omega=$ Equipment costs (GBP); $\sigma=$ Other Direct Costs (GBP); $\mu=$ Indirect costs (GBP) and; $\Psi=$ Borrowing costs (GBP). 
When people contribute content they are making their existing knowledge available for subsequent re-use within the organisation. If people spot opportunities to improve on current gaps then they are generating new knowledge. Experts can be identified from attendance at F2F meetings and they should then be made available to support others in improving which may lead to some form of knowledge transfer or shared experience between the parties. As a greater number of people become more competent in the required capabilities then there should be more opportunities for organisational successes which in the high value manufacturing industry are mostly related to market share, profitability and shareholder value.

\section{Implementing the Framework}

Implementing Dynamic KM in a large organisation, such as BAE Systems, should begin with engaging stakeholders. It is advised that this is then followed by a seven step process:-

1. data cleansing with agreed naming convention and meta-data policy agreement,

2. document and record management governance agreement,

3. access control agreement,

4. employee capability and competency profiling and development agreement,

5. personal and product performance reward and recognition agreement,

6. product portfolio profitability analysis and development agreement, and

7. change management and continuous improvement agreement. 


\section{Implications of Dynamic KM in High Value Manufacturing Industry}

During a project stakeholder meeting, the Dynamic KM framework was discussed. Profitability was a controversial metric for product development performance and participants thought that the data should be normalised with respect to time to compare projects when they have reached the same point of maturity. It is the opinion of the research team, however, that this data should not be normalised to time because time will be relative to labour costs, which is already a factor in the equation. From an investment perspective the better products are those that yield a positive return before and which is greater than other products. There was agreement from the project stakeholders that the phase of the Product Lifecycle Management process where the proposed Dynamic KM Framework was thought to have most benefit for BAE Systems was at the 'Front-end', specifically at 'Pre-key Decision Review' meetings where the product is 'New-New' (both new product and new process). The meeting participants were able to identify product development projects that went well and also those that did not go as well as they would have liked. The names of people who had stories of success and failure during those projects were identified. The importance of the capability and competency of engineers to reduce risk was also discussed during the meeting. The prototype service captured the spoken journey that the group took during the meeting. It captured real communication and the opinion from everyone who spoke. A real success story was also identified which followed on from an opportunity for improvement. It was found how that there are multiple people who have authority over the products areas, with a mixed matrix organisational structure making it difficult to pin-point a decision maker.

The developed framework and associated prototype could advance manufacturing practice by providing a video-history of meeting content so that 
organisational learning can be linked to decision making and the business of those decisions.

\section{Further work}

It is anticipated that as a workforce learns to maximise the demand for the products and reduce the complexity of operations to increase revenue and reduce overheads then a high value manufacturing organisation will be more profitable.

Further development of the prototype discussion board functionality so that user comments are assigned to the location of the media asset will also improve search discoverability of content. The presentation of the content in the web browser may also be re-developed so that there is easier navigation to the page with the video segments and discussion board. It would also be useful to have the variables that influence the profitability of the products to be displayed as a 'live-feed' on the page so that changes can be tracked against performance.

\section{Summary}

The expanded Dynamic KM Framework, which can be implemented into high value manufacturing industry, was created and the F2F meeting capture and indexing service was particularly well received by project stakeholders. Dynamic KM is convergence of man and machine working together in harmony to achieve profitable income for the company. The framework is designed to support organisational learning so that better informed decisions can be made during face-to-face meetings of tomorrow from the resultant actions of today. With Dynamic KM people will be rewarded for achieved performance metrics that improve the organisation's position in the market place. 


\section{Acknowledgements}

This document is based on work funded by EPSRC through BAE Systems. The researchers are deeply grateful to Nick Martin (Chief Technologist, BAE Systems Rochester), Clive Simmonds (Manufacturing Engineering Manager, BAE Systems Rochester) and all others for their support in making this study possible. Any opinions, findings and conclusions or recommendations expressed in this document are those of the authors and do not necessarily reflect those of EPSRC or BAE Systems. 


\section{References}

ATTARAN, M. 2007. Collaborative computing: a new management strategy for increasing productivity and building a better business. Business Strategy Series, $8(6), 387-393$.

BARCZAK, G., GRIFFIN, A. \& KAHN, K. B. 2009. PERSPECTIVE: Trends and Drivers of Success in NPD Practices: Results of the 2003 PDMA Best Practices Study. Journal of Product Innovation Management, 26 (1), 3-23.

BARNETT, T. J., HARDING, J. A. \& NURSE, A. 2010. Design and development of a classification system for knowledge management tools and methods. Proceedings of the Institution of Mechanical Engineers, Part B: Journal of Engineering Manufacture, 224 (6), 981-993.

BENN, N., BUCKINGHAM SHUM, S., DOMINGUE, J. \& MANCINI, C. 2008. Ontological foundations for scholarly debate mapping technology. In: 2nd International conference on computational models of argument (COMMA '08), 28-30 May, Toulouse, France, IOS Press.

BERINGS, M. G. M. C., POELL, R. F. \& SIMONS, P. R.-J. 2005. Conceptualizing Onthe-Job Learning Styles. Human Resource Development Review, 4 (4), 373-400.

BREDIN, K. 2008. People Capability of Project-based Organisations: A Conceptual Framework. International Journal of Project Management, 26 (5), 566-576.

BREDIN, K. 2010. Improving people capability of project-based organisations: a study of the change of HRM in two engineering-intensive firms. International Journal of Project Organisation and Management, 2 (4), 328-360.

BURGESS, D. 2005. What Motivates Employees to Transfer Knowledge Outside Their Work Unit? Journal of Business Communication, 42 (4), 324-348.

CABRERA, A., COLLINS, W. C. \& SALAGADO, J. F. 2006. Determinants of individual engagement in knowledge sharing. International Journal of Human Resource Management, 17 (2), 245-264.

CARLEY, K. M., DIESNER, J., REMINGA, J. \& TSVETOVAT, M. 2007. Toward an interoperable dynamic network analysis toolkit. Decision Support Systems, 43 (4), 1324-1347.

CHEN, H. H., KANG, H.-Y., XING, X., LEE, A. H. I. \& TONG, Y. 2008. Developing new products with knowledge management methods and process development management in a network. Computers in Industry, 59 (2-3), 242-253.

CHOI, B. \& LEE, H. 2003. An empirical investigation of KM styles and their effect on corporate performance. Information \& Management, 40 (5), 403-417.

CHUA, A. 2004. Knowledge management system architecture: a bridge between KM consultants and technologists. International Journal of Information Management, 24 (1), 87-98. 
DADZIE, A. S., BHAGDEV, R., CHAKRAVARTHY, A., CHAPMAN, S., IRIA, J., LANFRANCHI, V., MAGALHÃES, J., PETRELLI, D. \& CIRAVEGNA, F. 2009. Applying semantic web technologies to knowledge sharing in aerospace engineering. Journal of Intelligent Manufacturing, 20 (5), 611-623.

GUNASEKARAN, A. \& NGAI, E. W. T. 2007. Knowledge management in 21st century manufacturing. International Journal of Production Research, 45 (1), 2391-2418.

HENDERSON, K. M. \& EVANS, J. R. 2000. Successful implementation of Six Sigma: benchmarking General Electric Company. Benchmarking: An International Journal, 7 (4), 260 - 282.

HERTZUM, M. 2008. Collaborative information seeking: The combined activity of information seeking and collaborative grounding. Information Processing \& Management, 44 (2), 957-962.

JIN, H., NING, X., JIA, W., WUA, H. \& LU, G. 2008. Combining weights with fuzziness for intelligent semantic web search. Knowledge-Based Systems, 21 (7) 655-665.

KUMAR, S. \& GUPTA, Y. P. 1993. Statistical Process Control at Motorola's Austin Assembly Plant. Interfaces, 23 (2), 84-92.

KUO, T.-C., HUANG, S. H. \& ZHANG, H.-C. 2001. Design for manufacture and design for ' $\mathrm{X}$ ': concepts, applications, and perspectives. Computers \& Industrial Engineering, 41 (3), 241-260.

LOUADI, M. E. 2008. Knowledge heterogeneity and social network analysis - Towards conceptual and measurement clarifications. Knowledge Management Research \& Practice, 6 (3), 199-213.

MILTON, N. 2007. Quantifying your business case. KM Review. Melcrum Publishing, Magazine Article July-August 2007.

NONAKA, I. 1994. A Dynamic Theory of Organizational Knowledge Creation. Organization Science, 5 (1), 14-37.

NOY, N. F., CHUGH, A. \& ALANI, H. 2008. The CKC Challenge: Exploring Tools for Collaborative Knowledge Construction. IEEE Intelligent Systems, 23 (1), 6468

OKADA, A., TOMADAKI, E., BUCKINGHAM SHUM, S. \& SCOTT, P. J. 2008. Fostering Open Sensemaking Communities by Combining Knowledge Maps and Videoconferencing. UPGRADE, The European Journal for the Informatics Professional, 4 (3), 27-36.

PARASURAMAN, R. \& WICKENS, C. D. 2008. Humans: Still Vital After All These Years of Automation. Human Factors, 50 (3), 511-520.

PIORKOWSKI, B., GAO, J. \& EVANS, R. 2011a. A case-study: Finding references to product development knowledge from analysis of face-to-face meetings. In: J. 
Hesselbach and C. Herrmann, eds. Glocalized solutions for sustainability in manufacturing. Berlin/Heidelberg: Springer

PIORKOWSKI, B. A., EVANS, R. D. \& GAO, J. X. Development of a face-to-face meeting capture and indexing process. 15th international conference on computer supported cooperative work in design (CSCWD), 8-10 June, Ecole Polytechnique Federale de Lausanne, Switzerland, IEEE, 4-8.

PONS, D. 2008. Project management for new product development. Project Management Journal, 39 (2), 82-97.

RENZL, B. 2008. Trust in management and knowledge sharing: The mediating effects of fear and knowledge documentation. Omega, 36 (2), 206 - 220.

SALAS, E., COOKE, N. J. \& ROSEN, M. A. 2008. On Teams, Teamwork, and Team Performance: Discoveries and Developments. Human Factors, 50 (3), 540-547.

SERENKO, A., BONTIS, N. \& HARDIE, T. 2007. Organizational size and knowledge flow: a proposed theoretical link. Journal of Intellectual Capital, 8 (4). 610-627.

SNOWDEN, D. J. \& BOONE, M. E. 2007. A leader's Framework for Decision Making. Harvard Business Review 1-9.

SPEAR, S. \& BOWEN, H. K. 1999. Decoding the DNA of the Toyota Production System. Harvard Business Review, September-October 96-106.

WANG, J., CLEMENTS, M., YANG, J., DE VRIES, A. P. \& REINDERS, M. J. T. 2010. Personalization of tagging systems. Information Processing \& Management, 46 (1), 58-70.

YAO, J., RAGHAVAN, V. V. \& WUB, Z. 2008. Web information fusion: A review of the state of the art. Information Fusion, 9 (4), 446-449. 